\title{
PELATIHAN PEMBUKUAN SEDERHANA PADA KELOMPOK PRODUKSI DANGKRIK “GEDHANG KRIPIK” DUSUN KULUBANYU KABUPATEN MOJOKERTO
}

\author{
Iqbal Eka Sutawijaya ${ }^{*}$ \\ ${ }^{1}$ Universitas Negeri Surabaya, Indonesia \\ *Penulis Koresponsensi, email: iqbal.18037@mhs.unesa.ac.id
}

Received:19/01/2022

Revised:30/01/2022

Accepted:02/02/2022

\begin{abstract}
Entrepreneurship is one of the factors in improving the economy in Indonesia through community economic empowerment. Entrepreneurship runs which one of is through Micro, Small and Medium Enterprises (MSME) is expected to utilize the available natural resources with properly, and then be able to have idea and creativity in manage them. One of the hamlets that produce banana plantations is Kulubanyu Hamlet. This hamlet is located in Tawangrejo Village, Mojokerto Regenct, East Java Province. The assistance was held by the village development team from State University of Surabaya for the residents of Kulubanyu Hamlet which resulted in product creations, namely Dangkrik "Gedhang Kripik". An important factor in forming a new business by the residents of Kulubanyu Hamlet, except in product innovation, is also related to an understanding of financial management. So the village development team choosed to make counseling, training and mentoring activities for the Dangkrik business group regarding simple bookkeeping. The method that used by the village development team is simple bookkeeping training which runs for 2 months, the period of activity starting on August 18, 2019 and ending October 19, 2019. In the mentoring activity, the Kulubanyu Hamlet production group has been able to implementing simpe bookkeeping.
\end{abstract}

Keywords: Entrepreneurship, MSME, Dangkrik “Gedhang Kripik”, Simple Bookkeeping

\begin{abstract}
Abstrak. Kewirausahaan merupakan salah satu faktor dalam peningkatan perekonomian di Indonesia melalui pemberdayaan ekonomi masyarakat. Kewirausahaan yang dijalankan salah satunya melalui Usaha Mikro Kecil Menengah (UMKM) diharapkan untuk memanfaatkan sumber daya alam yang tersedia dengan baik, serta mampu untuk menyalurkan ide dan kreativitas dalam mengelolanya. Salah satu dusun yang menghasilkan hasil perkebunan pisang yaitu dusun Kulubanyu, dusun Kulubanyu sendiri terletak di Desa Tawangrejo, Kabupaten Mojokerto, Provinsi Jawa Timur. Diadakan Pendampingan yang dilakukan oleh tim bina desa pada warga Dusun Kulubanyu yang mana menghasilkan kreasi produk yaitu Dangkrik "Gedhang Kripik". Faktor penting dalam membentuk sebuah usaha baru oleh warga Dusun Kulubanyu selain dalam inovasi produk juga diperlukan terkait pemahaman mengenai pengelolaan keuangan. Maka dari itu dibuatlah kegiatan penyuluhan, pelatihan dan pendampingan kepada kelompok usaha Dangkrik oleh tim program Program Hibah Bina Desa (PHBD) mengenai pembukuan sederhana. Metode yang dilakukan yaitu pelatihan pembukuan sederhana yang berjalan selama 2 bulan dalam kurun waktu pelaksanaan kegiatan dimulai 18 Agustus 2019 dan berakhir 19 Oktober 2019. Pada kegiatan pendampingan kelompok produksi Dusun Kulubanyu telah mampu melaksanakan penerapan pembukuan sederhana.
\end{abstract}

Kata Kunci: Kewirausahaan, UMKM, Dangkrik “Gedhang Kripik”, Pembukuan Sederhana

How to Cite: Sutawijaya, I. E. (2022). Pelatihan Pembukuan Sederhana pada Kelompok Produksi Dangkrik "Gedhang Kripik" Dusun Kulubanyu Kabupaten Mojokerto. Mitra Mahajana: Jurnal Pengabdian Masyarakat, 3(1), 57-64. doi: https://doi.org/10.37478/mahajana.v3i1.1599

\section{PENDAHULUAN}

Salah satu faktor untuk meningkatkan perekonomian Indonesia yaitu melalui kewirausahaan yang dijalankan oleh masyarakatnya. Menurut Peraturan Menteri Negara Koperasi dan Usaha Kecil dan Menengah Republik Indonesia No 04/Per/M.KUKM/IX/2010, yang dimaksud kewirausahaan yaitu sebuah perilaku atau sikap seseorang dalam menangani usaha yang mengarah pada menciptakan cara kerja dengan lebih efisien dalam rangka untuk memberikan pelayanan yang lebih baik atau memperoleh laba yang lebih besar (Menteri Koperasi dan Usaha Kecil dan Menengah Republik Indonesia, 2010). Kewirusahaan banyak digeluti oleh masyarakat Indonesia khususnya pelaku UMKM dan berdampak positif salah satunya terhadap menurunya angka pengangguran di Indonesia (Wahyuningsih et al., 2017). 
Menurut data Kementerian Koperasi dan UKM, UMKM berkontribusi pada perekonomian Indonesia dengan menyerap $97 \%$ dari total tenaga kerja.

Kewirausahaan yang dijalankan melalui Usaha Mikro Kecil Menengah (UMKM) diharapkan mampu untuk memanfaatkan sumber daya alam yang tersedia dengan baik, serta mampu untuk menyalurkan ide dan kreativitas dalam mengelolanya (Laily \& Efendi, 2020). Usaha mikro kecil menengah (UMKM) sering kali dihubungkan dengan situasi terkini yang sedang dialami masyarakat, seperti peningkatan angka pengangguran, kemiskinan, tingkat pendidikan yang masih rendah, dan dampak negatif lainnya (Yonaldi, 2018). Menurut data yang diperoleh dari Badan Pusat Statistik (BPS) jumlah UMKM di Indonesia pada tahun 2020 mencapai 64 juta unit, meningkat dibandingkan dengan tahun 2018 yang jumlahnya 62 juta unit. Namun peningkatan jumlah UMKM dari tahun ke tahun tidak diselaras dengan peningkatan kinerja keuangan, karena masih minimnya kesadaran mengenai pentingnya pengelolaan keuangan pada pelaku usaha (Ramayani et al., 2021).

Usaha besar atau kecil pasti membutuhkan pengelolaan keuangan yang baik, khususnya dalam proses akuntansi atau pembukuan. Menurut Undang-undang nomor 28 tahun 2007, yang dimaksud pembukuan merupakan sebuah proses pencatatan keuangan secara teratur dalam rangka untuk memperoleh data dan informasi keuangan yang diantaranya yaitu aset, liabilitas, ekuitas, pendapatan dan beban (Peraturan Pemerintah RI, 2007). Serta total harga perolehan dari penyerahan barang dan jasa dengan ditutup oleh penyusunan laporan keuangan. Tujuan dibuatnya laporan keuangan adalah sebagai wadah informasi posisi keuangan dan kinerja keuangan bagi pihak yang berkepentingan dalam memutuskan sebuah keputusan (Wahyuningsih et al., 2017). Penggunaan standar pencatatan laporan keuangan yang dibutuhkan dan mudah untuk dipahami oleh pelaku UMKM yaitu Standar Akuntansi Keuangan Entitas Mikro Kecil dan Menengah (SAK EMKM). SAK EMKM diterbitkan oleh Ikatan Akuntansi Indonesia (IAI) yang ditujukan untuk pelaku UMKM yang belum mampu untuk memenuhi persyaratan akuntansi yang diatur dalam Standar Akuntansi Keuangan Entitas Tanpa Akuntansi Publik (SAK ETAP) (Uno et al., 2019).

Kabupaten Mojokerto memiliki banyak potensi sumber daya alam yang melimpah dengan hasil perkebunan, seperti durian, coklat, pepaya, dan pisang. Salah satu dusun yang menghasilkan hasil perkebunan pisang yaitu dusun Kulubanyu, dusun Kulubanyu sendiri terletak di Desa Tawangrejo, Kabupaten Mojokerto, Provinsi Jawa Timur. Dusun Kulubanyu berada tepat pada daerah Pegunungan Welirang dimana daerah tersebut sangat cocok untuk digunakan sebagai lahan perkebunan atau pertanian. Salah satu mata pencahariaan para warga dusun yaitu berkebun pisang. Pisang yang menjadi hasil perkebunan dijual secara langsung oleh warga, namun nilai jual secara langsung terbilang masing kurang tinggi, serta ketahanan pisang yang mudah untuk membusuk dapat merugikan warga karena tidak akan laku terjual. Maka dari itu perlu adanya inovasi agar meningkatkan nilai ekonomi hasil kebun pisang tersebut, namun dari warga Dusun Kulubanyu masih minim mengenai pengetahuan dan kreativitas dalam mengelola hasil kebun pisang serta pemanfaatan peluang bisnis.

Oleh karena itu, Himpunan Mahasiswa Jurusan Akuntansi Universitas Negeri Surabaya melalui Program Hibah Bina Desa (PHBD) yang diselengarakan oleh Kementerian Pendidikan dan Kebudayaan mengadakan sebuah program kerja pengabdian masyarakat yaitu Akuntansi Bina Desa (AKUBISA). Kegiatan ini bertujuan untuk membantu memberikan solusi terkait permasalahan yang dihadapi oleh warga Dusun Kulubanyu, dengan mengembangkan SDM dan memanfaatkan secara optimal sumber daya alam yang ada, khususnya hasil kebun pisang. Pendampingan yang dilakukan pada warga Dusun Kulubanyu menghasilkan kreasi produk yaitu Dangkrik "Gedhang Kripik". Produk Dangkrik sangat bergizi serta memiliki beraneka ragam rasa, sehingga nilai jual menjadi lebih tinggi.

Faktor penting dalam membentuk sebuah usaha baru oleh warga Dusun Kulubanyu selain dalam inovasi produk juga diperlukan terkait pemahaman mengenai pengelolaan keuangan. Permasalahan pengelolaan keuangan sangat umum dan sering kali dijumpai pada UMKM yang 
ada di Indonesia, salah satu contohnya yaitu masih banyaknya kejadian tercampurnya keuangan usaha dengan keuangan pribadi serta kurangnya metode pencatatan yang dilakukan (Maulani et al., 2016). Selain itu masih banyak pelaku UMKM yang terkendala dalam penetapan harga jual yang tepat, sehingga keuntungan keuntungan yang didapatkan kurang maksimal (Widhiastuti et al., 2019). Belum terealisasinya sistem pencatatan keuangan dengan baik, menyebabkan pelaku usaha tidak dapat melakukan monitoring terhadap arus keuangan perusahaan (Winarno et al., 2020). Pencatatan laporan keuangan yang baik memiliki manfaat salah satunya yaitu dapat memberikan informasi keuangan yang membantu pihak yang berkepentingan dalam menilai usaha tersebut saat ini dan kedepannya. Maka dari itu, perlu diadakannya pelatihan pembukuan sederhana untuk meningkatkan pemahaman warga Dusun Kulubanyu dalam mengelola keuangan pada usaha Dangkrik.

\section{METODE PELAKSANAAN}

Berdasarkan penjelasan sebelumnya bahwa permasalahan yang sedang dihadapi oleh kelompok usaha Dangkrik di Dusun Kulubanyu Desa Tawangrejo Kabupaten Mojokerto yaitu minimnya pengetahuan mengenai pengelolaan keuangan serta pencatatan laporan keuangan. Maka dari itu perlu untuk diadakannya penyuluhan, pelatihan dan pendampingan kepada kelompok usaha Dangkrik oleh tim program Program Hibah Bina Desa (PHBD) mengenai pembukuan sederhana. Metode yang dilakukan tim bina desa yaitu pelatihan pembukuan sederhana yang berjalan selama 2 bulan dalam kurun waktu 18 Agustus 2019 sampai dengan 19 Oktober 2019.

Berikut rincian kegiatan pelatihan pembukuan sederhana oleh tim program Akuntansi Bina Desa antara lain:

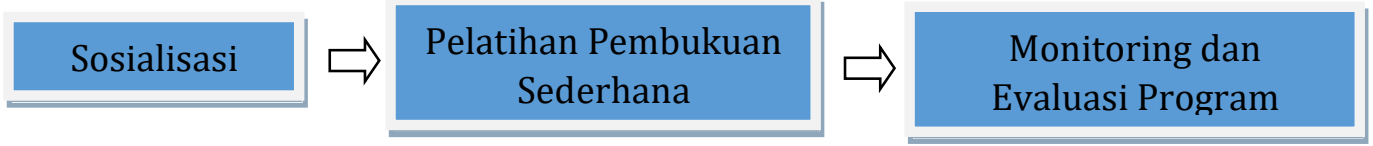

Gambar 1. Pelaksanaan Program Akuntansi Bina Desa

Deskripsi kegiatan yang dilakukan adalah sebagai berikut:

1. Sosialisasi

Langkah pertama yang dilakukan oleh tim bina desa yaitu melakukan sosialisasi mengenai pentingnya penyusunan laporan keuangan bagi UMKM. Dalam kegiatan sosialisasi ini kelompok produksi diberikan pemahaman mengenai tujuan dan manfaat penyusunan laporan keuangan. Kegiatan ini dilakukan selama satu hari yaitu pada tanggal 18 Agustus 2019.

2. Pelatihan Pembukuan Sederhana

Langkah selanjutnya yang dilakukan oleh tim bina desa yaitu melakukan pelatihan terkait pembukuan sederhana untuk kelompok produksi. Dalam kegiatan pelatihan ini tim bina desa memberikan contoh terlebih dahulu mengenai buku harian, laporan posisi keuangan dan laporan laba rugi. Setelah itu tim akan memberikan kertas kerja kepada warga untuk digunakan sebagai praktek secara langsung. Kegiatan ini berlangsung selama satu hari yaitu pada tanggal 24 Agustus 2019.

3. Monitoring dan Evaluasi Program

Langkah terakhir yaitu monitoring dan evaluasi program, kegiatan ini dilakukan oleh tim bina desa untuk melihat keberhasilan program. Kegiatan ini bersifat diskusi yang dilakukan oleh tim bina desa dengan kelompok produksi. Kegiatan ini dilakukan selama 4 kali dalam kurun waktu 1 September 2019 sampai dengan 19 Oktober 2019. 


\section{HASIL DAN PEMBAHASAN}

Kegiatan pengabdian kepada kelompok usaha di Dusun Kulubanyu Desa Tawangrejo Kabupaten Mojokerto dilakukan selama 6 bulan, namun terkait kegiatan pelatihan pembukuan sederhana dilaksanakan hanya selama 2 bulan. Dipilihnya Dusun Kulubanyu untuk kegiatan ini karena respon masyarakat yang sangat baik pada saat survei serta daerah Dusun Kulubanyu yang kaya akan sumber daya alam, khususnya kebun pisang. Sebelum melakukan kegiatan, tim bina desa terlebih dahulu menemui perangkat desa untuk meminta izin melakukan kegiatan bina desa, serta menjelaskan kegiatan yang akan dilakukan selama 6 bulan kedepan.

\section{Pengarahan Awal}

Kegiatan awal yang dilakukan oleh tim bina desa yaitu melakukan peninjauan terkait permasalahan yang ada, serta pengajuan rencana program kegiatan PHBD untuk kedepannya dari tim bina desa dan telah disetujui oleh warga Dusun Kulubanyu. Rencana program kegiatan yang telah dibuat dapat membantu tim bina desa dan warga Dusun Kulubanyu dalam mencapai target-target yang telah ditetapkan selama periode yang ditentukan dan membantu tim bina desa melakukan monitoring serta evaluasi kegiatan.

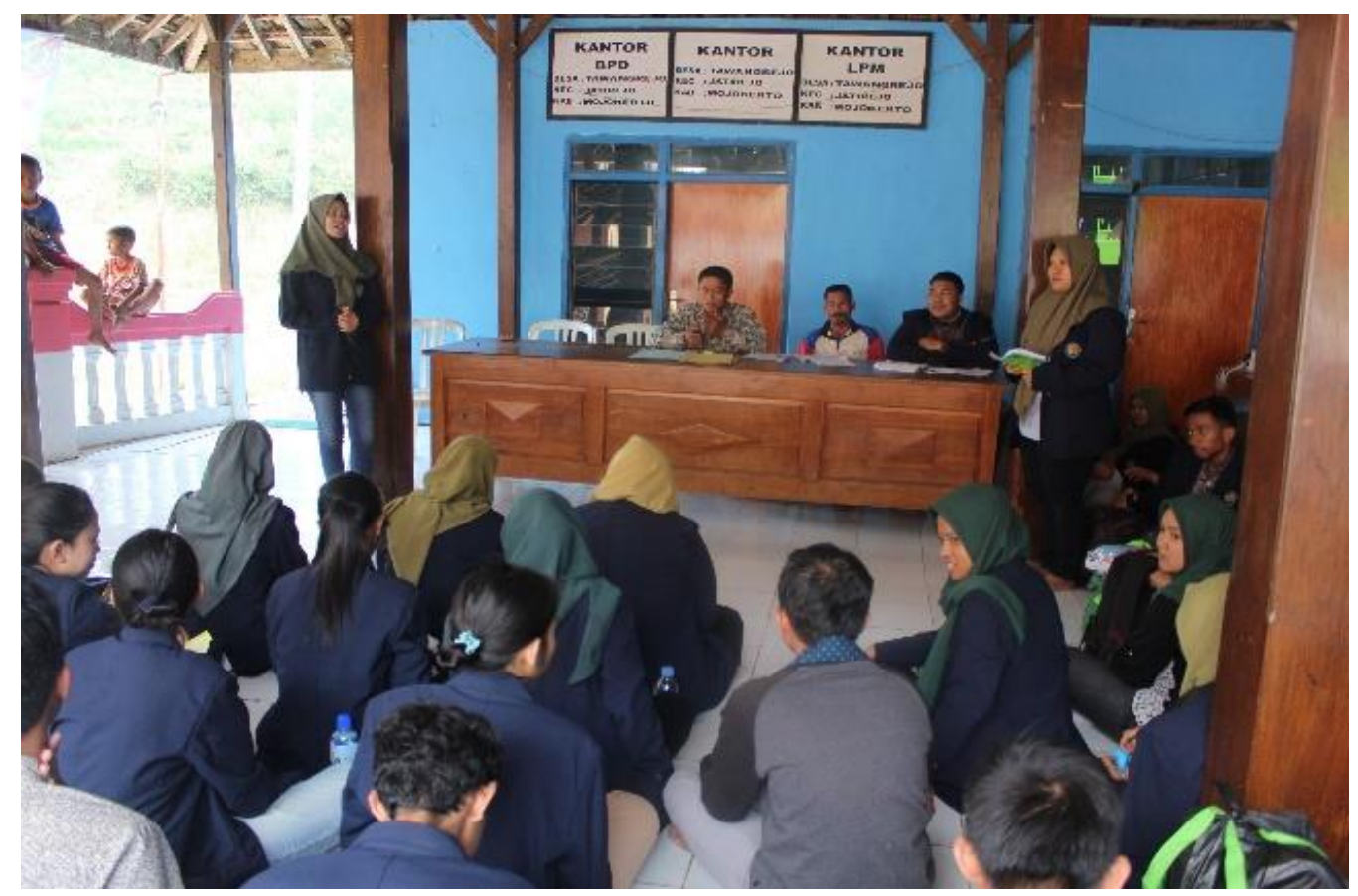

Gambar 2. Pengarahan Awal

\section{Pembentukan Kelompok Produksi}

Kegiatan selanjutnya yaitu diskusi dengan warga Dusun Kulubanyu mengenai pembagian kelompok usaha Dangkrik yang disesuaikan dengan rasa-rasa dari produk Dangkrik, dari hasil yang diperoleh terbentuk ditetapkan 4 kelompok yang beranggotakan ibu-ibu rumah tangga Dusun Kulubanyu. Setiap kelompok memiliki masing-masing 1 orang sebagai ketua, hal tersebut bertujuan untuk membantu proses produksi berjalan dengan terarah dengan baik. Setiap kelompok produksi memiliki rumah produksi yang bertempat pada salah satu anggota kelompok, pemilihan tempat produksi yang bersih dan nyaman juga dilakukan agar menghasilkan produk Dangkrik yang higienis.

Setelah pembentukan kelompok produksi, tim bina desa akan membentuk tim pemasaran yang terdiri dari salah satu perwakilan masing-masing kelompok produksi, penjualan produk Dangkrik pada awalnya akan dipasarkan di wilayah Mojokerto dan Surabaya. 


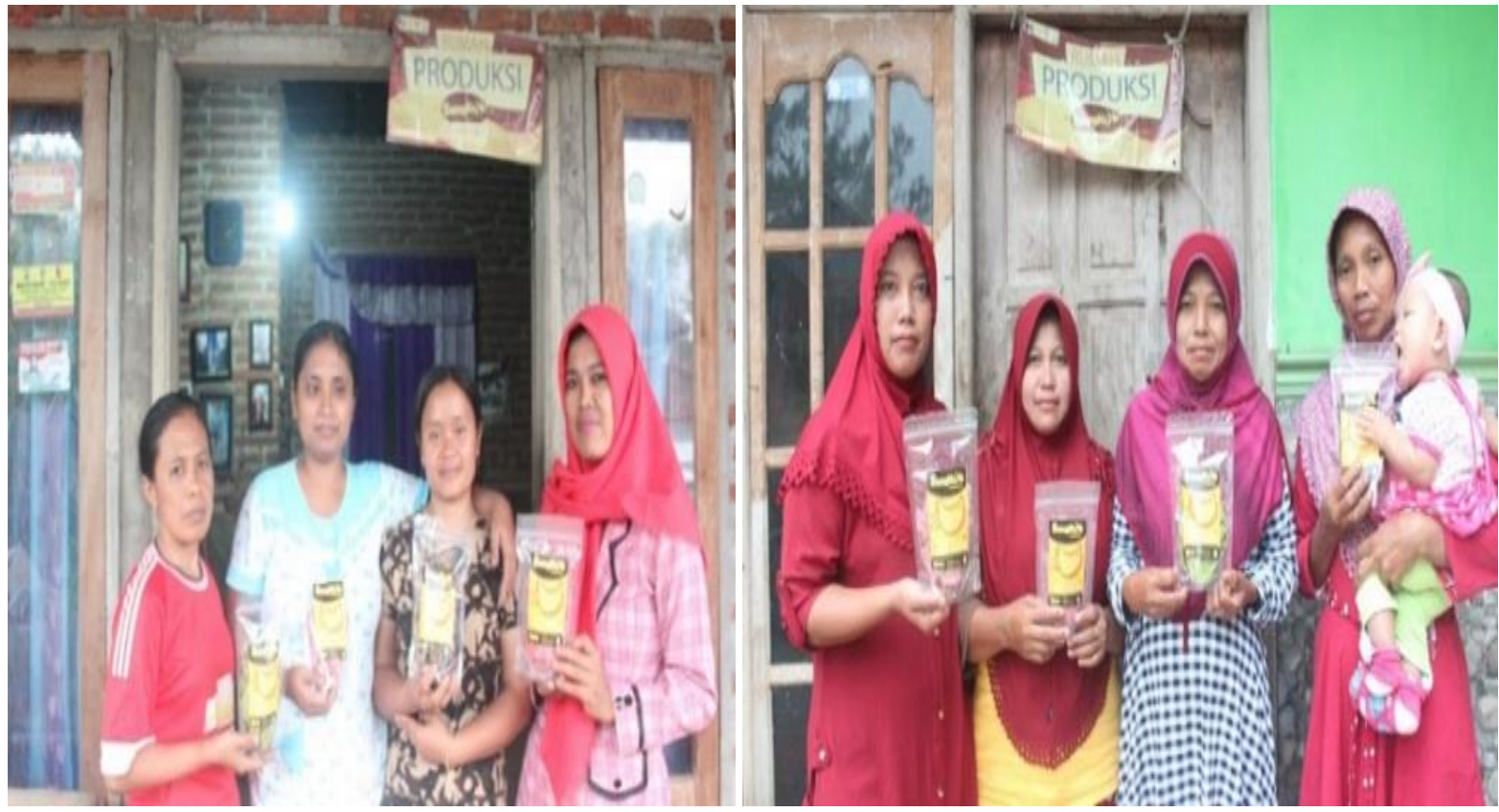

Gambar 3. Kelompok Produksi

\section{Pelatihan dan pendampingan Pembukuan Sederhana}

Pelaksanaan kegiatan pelatihan pembukuan sederhana bertujuan untuk memberikan wawasan kepada kelompok produksi Dangkrik Dusun Kulubanyu mengenai pentingnya pengelolaan keuangan dan pencatatan laporan keuangan. Setelah kegiatan pelatihan ini diharapkan kelompok produksi dapat mengelola keuangan usaha, serta memisahkan keuangan usaha dengan keuangan pribadi, sehingga dapat melihat perkembangan dari usaha Dangkrik. Materi yang digunakan dalam pembukuan keuangan sederhana yaitu buku harian, laporan posisi keuangan dan laporan laba rugi. Pada kegiatan pendampingan kelompok produksi Dusun Kulubanyu telah mampu melaksanakan penerapan pembukuan sederhana.
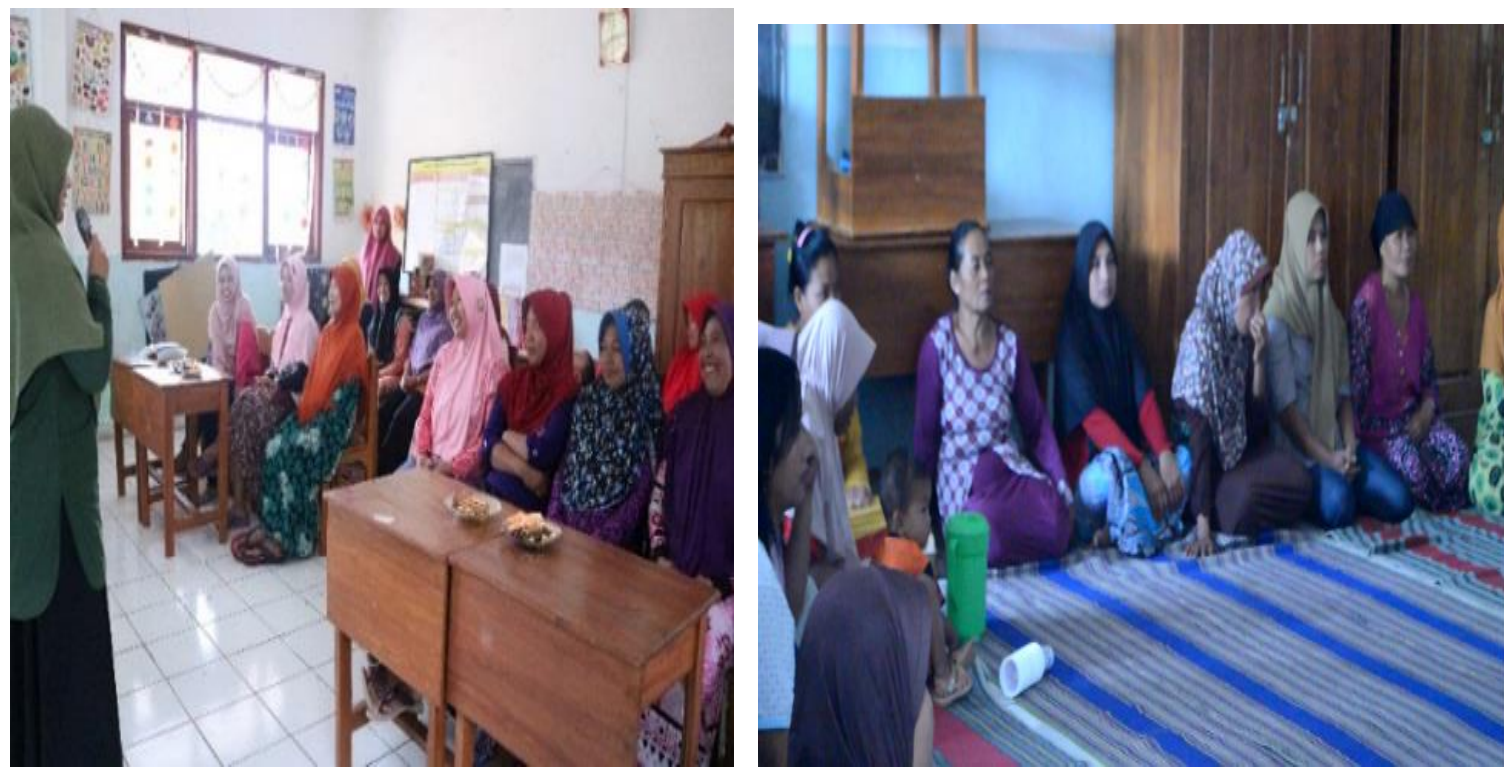

Gambar 4. Pelatihan dan Pendampingan Kelompok Produksi

Berikut contoh format kertas kerja pelatihan pembukuan sederhana yang dilakukan oleh tim bina desa: 
a) Buku Harian

\section{BUKU HARIAN}

Buku Penerimaan Kas

\begin{tabular}{|c|c|c|c|c|c|c|c|}
\hline \multirow{2}{*}{ Tanggal } & \multirow{2}{*}{ Keterangan } & \multirow{2}{*}{ Ref } & \multirow{2}{*}{ Piutang } & \multirow{2}{*}{ Penjualan } & \multicolumn{2}{|c|}{ Lain-Lain } & \multirow{2}{*}{ Saldo } \\
\hline & & & & & Perkiraan & Jumlah & \\
\hline & & & & & & & \\
\hline & & & & & & & \\
\hline & & & & & & & \\
\hline & & & & & & & \\
\hline & & & & & & & \\
\hline & & & & & & & \\
\hline & & & & & & & \\
\hline & & & & & & & \\
\hline & & & & & & & \\
\hline
\end{tabular}

Buku Pengeluaran Kas

\begin{tabular}{|c|c|c|c|c|c|c|c|}
\hline \multirow{2}{*}{ Tanggal } & \multirow{2}{*}{ Keterangan } & \multirow{2}{*}{ Ref } & \multirow{2}{*}{ Utang } & \multirow{2}{*}{ Pembelian } & \multicolumn{2}{|c|}{ Lain-Lain } & \multirow{2}{*}{ Saldo } \\
\hline & & & & & Perkiraan & Jumlah & \\
\hline & & & & & & & \\
\hline & & & & & & & \\
\hline & & & & & & & \\
\hline & & & & & & & \\
\hline & & & & & & & \\
\hline & & & & & & & \\
\hline & & & & & & & \\
\hline & & & & & & & \\
\hline & & & & & & & \\
\hline
\end{tabular}

Gambar 5. Format Form Buku Harian

b) Laporan Laba Rugi

\section{LAPORAN LABA RUGI}

\begin{tabular}{|l|}
\hline PENDAPATAN \\
Pendapatan Usaha \\
Pendapatan Lain-lain \\
Jumlah Pendapatan \\
BEBAN \\
Beban Usaha \\
Beban Lain-lain \\
Jumlah Beban \\
Total Laba (Rugi) \\
\hline
\end{tabular}

Gambar 6. Format Form Laporan Laba Rugi 


AKTIVA
Aktiva Lancar:
Kas
Piutang
Persediaan
Aktiva Tetap
Tanah dan Bangunan
Peralatan
Jumlah Aktiva
PASIVA
Utang Jangka Pendek:
Utang Dagang
Utang Jangka Panjang:
Jumlah Pasiva
EKUITAS
Modal
Jumlah Ekuitas

Gambar 7. Format Form Laporan Posisi Keuangan

\section{SIMPULAN DAN TINDAK LANJUT}

Sebelum pelaksanaan program PHBD melalui kegiatan AKUBISA, warga Dusun Kulubanyu masih belum memilliki pemahaman mengenai pengelolaan keuangan serta pencataan laporan keuangan. Hal ini dikarenakan minimnya literasi mengenai pengelolaan keuangan. Maka dari itu kegiatan pelatihan pembukuan sederhana sangatlah membantu warga Dusun Kulubanyu, khususnya kelompok produksi Dangkrik dalam mengelola keuangan usahanya. Pelatihan pembukuan sederhana dilaksanakan selama 2 bulan dan selalu dihadiri lebih dari $90 \%$ total warga yang diundang. Penilaian keberhasilan oleh tim bina desa dilihat pada saat kegiatan pendamingan, dimana warga Dusun Kulubanyu telah menerapkan pembukuan sederhana dengan baik.

\section{UCAPAN TERIMAKASIH}

Penulis mengucapkan terimakasih kepada Kementerian Pendidikan dan Kebudayaan yang telah mendanai Program Holistik Bina Desa 2019 (PHBD) sehingga dapat disalurkan kepada warga Dusun Kulubanyu melalui kegiatan AKUBISA. Serta penulis ucapkan terimakasih sebanyak-banyaknya kepada seluruh perangkat desa di Dusun Kulubanyu Desa Tawangrejo yang telah memberikan izin untuk melaksanakan program bina desa, serta memberikan pengarahan dan masukan sehingga kegiatan bina desa dapat berjalan dengan baik. Tidak lupa juga penulis ucapkan terimakasih kepada Dosen pembimbing dan Anggota tim PHBD Himpunan Mahasiswa Jurusan Akuntansi Fakultas Ekonomika dan Bisnis Universitas Negeri Surabaya yang telah berkontribusi dalam menyukseskan kegiatan ini.

\section{DAFTAR PUSTAKA}

Laily, N., \& Efendi, D. (2020). Pelatihan Pembukuan Sederhana Bagi Wanita Wirausaha Batik Jonegoro Di Kabupaten Bojonegoro. Jurnal Layanan Masyarakat (Journal of Public Services), 3(1), 43. https://doi.org/10.20473/jlm.v3i1.2019.43-46 
Maulani, T. S., Dialysa, F., \& Prawirasasra, K. P. (2016). Pelatihan Pembukuan Keuangan Sederhana dan Motivasi Kewirausahaan Pada Kelompok Usaha Makanan RW 02 Kelurahaan Neglasari Kecamatan CIbeunying Kaler Bandung. Jurnal Dharma Bhakti STIE Ekuitas, 01(01), 32-37.

Menteri Koperasi dan Usaha Kecil dan Menengah Republik Indonesia. (2010). Peraturan Menteri Negara Koperasi dan Usaha Kecil dan Menengah Republik Indonesia Nomor 04/Per/M.KUKM/IX/2010 Tentang Pedoman Program Pertumbuhan dan Pengembangan Sarjana Wirausaha.

Peraturan Pemerintah RI. (2007). Undang-Undang Republik Indonesia Nomor 28 Tahun 2007 Tentang Perubahan Ketiga Atas Undang-Undang Nomor 6 Tahun 1983 Tentang Ketentuan Umum dan Tata Cara Perpajakan (Vol. 3, Issue Juli).

Ramayani, R. F., Rosalina, A., \& Prabumulih, S. (2021). Pelatihan Akuntansi UMKM Untuk Meningkatkan Kinerja Keuangan Usaha Kelompok Tani Nanas Di Desa Karya Mulya Kecamatan Prabumulih Selatan. 3, 91-96.

Uno, M. O., Kalangi, L., Pen, R. J. A., Penerapan, A., Akuntansi, S., Entitas, K., Menengah, D. A. N., Emkm, S. A. K., Usaha, P., Menengah, D. A. N., Kasus, S., Rumah, P., Di, K., \& Gorontalo, K. (2019). Analisis Penerapan Standar Akuntansi Keuangan Entitas Mikro, Kecil, Dan Menengah (Sak Emkm) Pada Usaha Mikro, Kecil, Dan Menengah (Studi Kasus Pada Rumah Karawo Di Kota Gorontalo). Jurnal EMBA: Jurnal Riset Ekonomi, Manajemen, Bisnis Dan Akuntansi, 7(3), 3887-3898. https://doi.org/10.35794/emba.v7i3.24891

Wahyuningsih, E. D., Setiawati, I., \& Prasojo, T. A. (2017). Pemberdayaan Pelaku Usaha Mikro Dengan Memberikan. Prosidimg Seminar Nasional Publikasi Hasil-Hasil Penelitian Dan Pengabdian Masyarakat, September, 491-495.

Widhiastuti, R., Kardiyem, K., \& Farliana, N. (2019). Model Akuntansi Sederhana Bagi UMKM Makanan Kota Semarang. JPPM (Jurnal Pengabdian Dan Pemberdayaan Masyarakat), 3(1), 165. https://doi.org/10.30595/jppm.v3i1.4043

Winarno, A., Agustina, Y., Wijijayanti, T., Churiyah, M., \& Subagyo, S. (2020). Pelatihan Manajemen dan Pembukuan Dasar Bagi IKM Sanan Kota Malang. Jurnal KARINOV, 3(1), 58. https://doi.org/10.17977/um045v3i1p58-63

Yonaldi, S. (2018). Kewirausahaan Bagi Industri Kecil Menengah Di Kota Padang Dalam Rangka Peningkatan Kemampuan Manajemen Dan Perluasan Pasar. 1(September), 8-26. https://doi.org/10.31227/osf.io/wghfj 